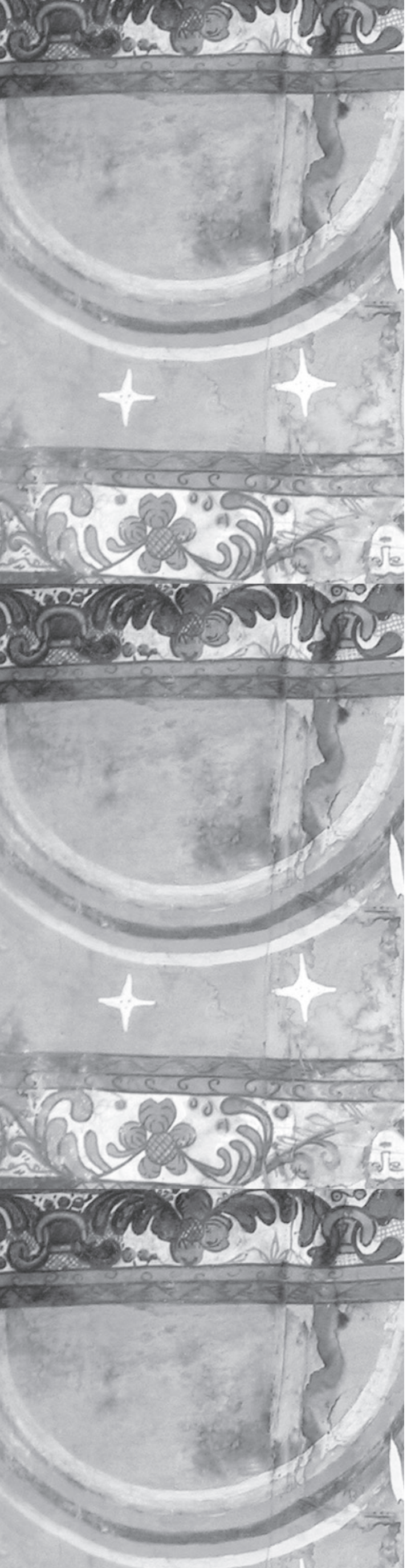

\title{
Para construir casas
}

\author{
Renata Schneider
}

Yo creo que estábamos mejor marginados. Eso dice Juan Martínez, que fue gobernador antes que yo, y yo pienso igual. Antes nos ayudábamos entre todos porque no había de otra. Luego llegó el gobierno. Nos dijo que la iglesia era de propiedad del país: dejó de ser del pueblo y ya era de México... y nos empezaron a ayudar. $Y$ nosotros nos fuimos dejando de ayudar. Yo por eso pienso que estaba mejor cuando estábamos marginados.

Félix Rubio Medina, gobernador pame, noviembre de 2006

E n 2002 fui invitada por una ONG a hacer el dictamen de los retablos principales de dos templos localizados en los poblados keres de San José de la Laguna y San Esteban de Acoma, Nuevo México. Los problemas eran absolutamente diferentes entre sí y las formas en que ambas comunidades se relacionaban con sus objetos sacros lo era también. Si en Acoma no pude trabajar porque no se me permitió tocar el retablo (por más que insistí en que debía hacerlo para poder realizar el dictamen y eventualmente restaurarlo), en Laguna la tribu me pidió que estudiara lo más que pudiera de la iglesia.

Lo primero que me llamó la atención fue la decoración mural de la nave del templo de San José, Ilena de motivos abstractos pintados en vinílica de distintos colores.

La pintura de Laguna no se relacionaba con la decoración mural de otros templos de la zona; tenía algo fuera de lugar. Comencé a preguntar sobre ella y supe que durante años la nave del templo había sido decorada por los warchiefs, quienes, tras encerrarse un par de días en la iglesia y recibir ofrendas y comidas del resto del grupo, soñaban en conjunto los motivos de la pintura (arco iris, soles, agua...) y la plasmaban ritualmente cada cierto tiempo por medio de arcillas coloreadas. Ocho años atrás los sacerdotes franciscanos que ofician las misas y tienen a su cargo el pequeño convento contiguo les propusieron hacer algo más duradero y en vez de la tradicional arcilla de soporte, usaron cemento: los warchiefs soñaron por última vez y pintaron los motivos con vinílicas. Y la gente dejó de prestar atención a los símbolos; tuvo, en cambio, una linda decoración.

En el área cora del estado de Nayarit, la Comisión Nacional para el Desarrollo de los Pueblos Indígenas decidió hace un par de años que era importante restaurar el templo colonial de Santa Teresa del Nayar. Durante el estudio preliminar, varios antropólogos especializados en esta zona me comentaron que, aunque se trataba de un templo — que nunca tuvo cubierta y jamás se ocupó- muy interesante desde el punto de vista histórico, para los vecinos del pueblo era simplemente un terreno baldío cercado; la iglesia que recono- 
cían como propia era el barracón con techo de lámina que se encontraba a unos cuantos pasos de la construcción jesuita. Hasta donde sé, el proyecto de restauración y rehabilitación fue desestimado y nunca se realizó.

Los ejemplos anteriores muestran casos interesantísimos que, como restauradores, nos hacen pensar en nuestra práctica profesional. En Laguna había dos posibilidades: decidir que no había nada que restaurar, o proponer que se removiera el cemento, que los warchiefs se reunieran de nuevo cada ciclo ritual y la nave se restaurara para, así, obtener "las pinturas originales" (donde la autenticidad buscada se manifestaba en la actividad pictórica, no en su resultado físico). En Santa Teresa del Nayar, la tendencia natural era buscar que se techara, limpiara, consolidara y rehabilitara el templo para que la comunidad lo ocupara como el verdadero espacio, sagrado y digno, que se merecía. La otra opción era simplemente dejar que siguieran usando lo que ellos reconocen como templo y se ideara una función alterna para el edificio histórico. En Acoma no había mucho que decir; quizá que en la reunión semanal de la tribu se le diera permiso a quién no fuera indígena de pisar el presbiterio.

En otra serie de casos, quizá los más abundantes, grupos establecidos o espontáneos de creyentes solicitan que sus objetos sacros se restauren de modo que se vean "bonitos", de modo que recobren "dignidad", de modo que recuperen su "trabajo"... En la mayor parte de los casos, esto implica realizar intervenciones que no siempre casan con las normas operativas de la disciplina y que son objeto de acaloradas discusiones entre especialistas: ¿es válido reponer la mano de la virgen que bendice si no existen fotografías previas que documenten su forma y aspecto general?; ¿ es necesario conservar 100 capas de repintes absolutamente degradados para que la gente reconozca a su san Miguel?

Para el ejercicio tradicional de la conservación-restauración, algunas de las posibles propuestas no son propiamente materia de trabajo de la disciplina o, cuando lo son, implican, como ya se dijo, intervenciones controvertidas. En algunos casos lo que destaca es la ausencia, o más bien la pérdida, de signos concretos de veneración hacia ciertas cosas, ciertos edificios (ies competencia de un restaurador influir en las decisiones de lo que un grupo social considera sagrado?). En otros, la imposibilidad de encontrar mecanismos inmediatos para restaurar objetos sacros (ies preciso que se conserven materialmente si sus usuarios principales no lo consideran necesario?). En los últimos, se corre el riesgo de ser marginado por los demás miembros de la profesión (¿es ético agregar partes perdidas y sin registro para hacer más funcional un objeto?).

Estos problemas, que desde la transición conceptual de la obra de arte a los bienes culturales cada día son más patentes, en México se han resuelto casi siempre de manera acrítica. En las pocas ocasiones en que se debaten, basados en argumentos muy confusos, los opositores a la teoría clásica (que siempre dicen que no y punto) pro- ponen que los objetos en sí mismos no significan nada, que las intervenciones se hacen para los usuarios, que trabajar para recuperar simplemente las condiciones materiales del objeto obviando su uso no tiene sentido, que las cualidades de autenticidad, integridad u otros ideales básicos de la conservación no forman parte realmente del objeto material, etcétera.

La pregunta inmediata frente a esta otra visión, empero, es si ello no implica siempre apelar a cada caso aisladamente, sin reglas generales por sobre las situaciones particulares, lo que desdibuja poco a poco — pero sustancialmente- los límites y alcances de cualquier profesión.

En este contexto, lo que quisiera mostrar aquí es que si bien el trabajo de la conservación-restauración tiene una dimensión epistemológica y otra moral, al abordar ambas esferas a la par, durante deliberaciones tripartitas con el objeto y sus usuarios, necesariamente deberemos guiarnos por una serie de principios normativos (o estándares constitutivos) que nos permitirían evitar procedimientos acríticos o extremamente casuísticos.

\section{Tendencias conceptuales}

En México, y probablemente en todo el mundo hispanohablante, la principal fuente normativa del ejercicio de la conservación-restauración es todavía la Teoría de la restauración de Cesare Brandi. Este libro es casi la única lectura conceptual obligatoria de las escuelas que forman especialistas en restauración en el país, y sus postulados normativos son básicamente los que dan lugar a la construcción de la ética de la restauración a nivel nacional (entendiendo aquí ética en la versión derivada del concepto, es decir, en lo que corrientemente se entiende como "ética médica" o "ética profesional"; esto es, ser fiel a los valores particulares que norman el carácter de un oficio o práctica).

De hecho, en los debates teóricos en general se apela a Brandi y poco o nada a las cartas normativas suscritas por México - aunque éstas, es claro, se aproximan en muchos casos a ciertas propuestas brandianas- o, peor aun, ni a sus leyes especificas.

Su planteamiento, disperso en una serie de textos escritos entre 1949 y 1961, retoma la corriente fenomenológica de Husserl y algunos aspectos del idealismo en sus versiones alemana e italiana. Simplificado (me tomaré esa libertad), postula que la obra de arte se compone de materia e imagen, y que su reconocimiento en conjunto se produce mediante una iluminación —revelación- de la conciencia (Brunel 2000).

Siguiendo a la fenomenología, lo fundamental aquí es el ámbito donde aparecen los hechos. Ese lugar es la conciencia: lo real es todo aquello que es pensado clara y distintamente, y que tiene la posibilidad de situarse en el tiempo. En concreto, su realidad es mental: "La diferencia entre la obra de arte y el objeto ordinario, y por consiguiente, la diferencia entre la reparación y la restau- 
ración, no es una cuestión de material o de técnica; recae únicamente en el reconocimiento del objeto como obra de arte" (Brunel 2000:10. Traducción de Valerie Magar).

La condición de posibilidad para que la identidad de la obra de arte se manifieste en la conciencia depende de una cualidad metafísica: la unidad potencial de la imagen. La unidad potencial indica la importancia de concebir el todo de la obra y comprender que ésta no se conforma de una suma de partes: de las partes deterioradas que vemos en primera instancia (Brandi 1998; Brunel 2000; González-Varas 1999). El momento en que la obra, como unidad, y como materia y aspecto, se ofrece a la conciencia es de inspiración idealista y es descrito como "la intuición de una conciencia particular que se siente como una conciencia universal" (Brunel 2000:11. Traducción de Valerie Magar). Lo esencialmente singular de esta iluminación es que la obra de arte, pese a encontrarse en un presente eterno, no escapa por ello al paso de los años: sigue siendo ella misma ante la conciencia. ${ }^{1}$

Brandi considera que esta manifestación de la unidad potencial de la imagen a la conciencia se logra mediante dos vías de acceso inseparables: las instancias estética e histórica. ${ }^{2}$ En el lenguaje del derecho, del cual, además de la historia del arte, provenía Brandi (Brunel 2000), las instancias son los distintos recursos por los cuales se debe pasar para llegar a la conclusión de un juicio (crítico en acto). ${ }^{3}$ Es importante recalcar aquí que la información que representa cada uno de estos recursos se encuentra en el objeto en el que está plasmada la obra de arte; es decir, los datos son constitutivos del objeto. Mediante las instancias y su adecuado estudio (tanto en el objeto mismo como en otros contextos), es posible recuperar la unidad potencial sin caer en falsificaciones o engaños.

\footnotetext{
1 "El reconocimiento de la obra de arte equivale a la pre-comprensión hermenéutica. Y es dentro de esa tradición — que permite la comprensión- que la obra se da como otra, como pasado. Hay a la vez contacto y distancia, familiaridad y extrañeza" (Philippot 1995:4-5. Traducción de Valerie Magar).

${ }^{2}$ Brandi no deja de ver la importancia de la funcionalidad de la obra de arte, noción fundamental en las reflexiones conceptuales actuales, pero da cuenta de ella en unas cuantas líneas. La supedita a las instancias estética e histórica y la olvida (Brandi 1998:15). Por otro lado, para González-Varas (1999) Brandi solventa con ellas el problema de la pelea Viollet-le-Duc-Ruskin, al poner en igual nivel las dos cualidades que cada uno de ellos defiende como base de la restauración (o de lo innecesario de la restauración, en el caso de Ruskin).

${ }^{3}$ El italiano divide la instancia histórica en tres momentos, conocidos dentro del gremio como historicidades: 1) el tiempo como duración del proceso creativo originario; 2) el tiempo como el intervalo de años que transcurre entre la conclusión de la creación de la obra de arte y su identificación en la conciencia - lo que en los últimos años se ha dado en Ilamar, con un concepto importado de las ciencias sociales, línea de vida- $y, 3$ ) el tiempo como el instante concreto de su revelación (Brandi 1998; González-Varas 1999).
}

Posteriormente, Brandi indica una serie de reglas operativo-normativas que orientan el juicio crítico. En México y gran parte del mundo (y no necesariamente presentadas así en los textos mismos), estas reglas se resumen en la mínima intervención, el respeto a la pátina, hacer distinguible la intervención. Todas ellas buscan respetar la obra de arte en tanto manifestación auténtica e íntegra para la conciencia y se adecuan a la información obtenida mediante las instancias estética e histórica. Es decir, hablamos ya del marco deontológico como tal, lo que comúnmente se conoce como la ética de la restauración.

La propuesta de Brandi funcionaba relativamente bien: la parte epistémica se consideraba medio indescifrable en el ejercicio cotidiano de la profesión (asuntos como que la falsedad está en el juicio pero no en el objeto suelen marearnos, por ejemplo), pero seguirla éticamente resultaba bastante fácil, al menos en el discurso: los debates se montaban alrededor de los grados en que las reglas operativas podían o no respetarse en la práctica, pero no se cuestionaba su capacidad normativa.

Sin embargo, e independiente de las críticas o adecuaciones, digamos internas, que hicieron autores como Paul Philippot o Dezzi Bardeshi (cf. González-Varas 1999; Philippot 1976 y 1995), desde finales de los setenta, y con más fuerza hacia finales del siglo XX, el concepto de patrimonio cultural comenzó a desestabilizar la propuesta brandiana, colándose poco a poco en sus fisuras. El componente metafísico de la obra de arte se desdibujó; acompañándola aparecieron un sinfín de objetos (para restaurar) que clara y llanamente eran sólo construcciones sociales:

El patrimonio cultural es construido cognitivamente [...]. Es un hecho social, y como todos los actos sociales, es tanto pasivo como activo. Su pasividad descansa en su papel como campo de selección: la mayor parte de los elementos (cualquiera que sea su tipo) no logran colarse en la zona patrimonial. Su actividad descansa en su influencia: una vez que elementos particulares han sido establecidos como patrimonio, ejercen poder, tienen una vida propia que afecta las mentes de las personas y por tanto afecta sus elecciones (Pearce 2000:59. Traducción de la autora).

Acceder a construcciones sociales que usualmente no sintetizan características universales mediante casos particulares depende de diversas capacidades, ya no de revelaciones: capacidades no contempladas por Brandi, entre ellas, y muy fundamentalmente, de la acertada lectura de una serie de características atribuidas al objeto (que se ha de restaurar) por diversos actores o discursos sociales durante el transcurso de su vida material.

Hoy en día este problema se ha solucionado apelando a una especie de teoría de los valores aplicada a la restauración cuyo corpus paradigmático sería la compilación 
Values and Heritage Conservation, realizada en el año 2000 por Erika Avrami, Randall Mason y Marta de la Torre a nombre del Getty Conservation Institute. A mi juicio, esta propuesta, muy útil si se maneja dentro de sus justos límites, conlleva tres consecuencias negativas: 1 ) atomiza los objetos que construyen nuestro campo de estudio; 2) convierte a su vez en objetos a los sujetos que valoran los bienes que debemos restaurar, y, 3) es muy fácil de trivializar (aspecto que sólo mencionaré brevemente en una nota al pie).

Como ejemplo emblemático de lo que quiero señalar en los dos primeros casos, me detendré en Salvador Muñoz, otro de los referentes conceptuales más socorridos hoy en día en el mundo de la conservaciónrestauración de habla hispana. En una pequeña pero importante sección de su Teoría contemporánea de la restauración, este autor retoma la propuesta que el italiano Giorgio Bonsanti hace del giro copernicano (Muñoz 2003:37-48). La idea primordial de Bonsanti está descrita más o menos así: "el elemento característico de la restauración no está en el objeto, sino en el sujeto [...]. Restauración es lo que los restauradores dicen que es la restauración". La proposición es más que interesante y permite evadir temas problemáticos tan antiguos que vienen desde los inicios de la filosofía griega, como son la autenticidad material de un objeto o la integridad de sus partes. Esta "revolución" o giro es la base misma de la teoría kantiana y ha sido usada por muchas disciplinas para postular nuevos referentes lógicos, aunque es importante señalar que, en la frase final, Bonsanti parece confundir el giro copernicano con el relativismo. ${ }^{4}$

Muñoz, sin embargo, está interesado en indicar que, además de nosotros y el objeto, hay un tercero, el que significa al objeto. La propuesta que domina todo su libro es la siguiente:

a medio camino entre la resignación lógica de Bonsanti y el optimismo ingenuo de las teorías clásicas [la teoría contemporánea de la Restauración] admite que la Restauración se define en función de sus objetos, pero defiende que lo que caracteriza esos objetos son rasgos de tipo subjetivo, establecidos por las personas, y no inherentes a los propios objetos. Los objetos de Restauración se caracterizan porque gozan de una consideración especial por parte de ciertos sujetos, que no son necesariamente, ni siquiera mayoritariamente, los restauradores: la relación entre todos estos objetos es su carácter simbólico (Muñoz 2003: 40).

Lo que Muñoz olvida es que la revolución copernicana no implica un tercer participante: en esta operación de construcción de nuestro objeto-mundo no hay espacio

\footnotetext{
${ }^{4}$ Véase Kant (1978:BXVI, 19-20). El filósofo habla de las estructuras de conocimiento de un sujeto universal, no de las formas específicas en que aborda(n) el conocimiento un(os) sujeto(s) particular(es).
}

para introducir otro elemento cognoscente. Hay un sujeto cognoscente y un objeto de conocimiento. Así, la idea kantiana propone que el mundo es como es porque tenemos (como sujetos) unas estructuras formales cognitivas específicas que nos permiten verlo solamente así y no de otra manera.

Como las categorías mediante las cuales conocemos son estructuras formales, están vacías. Esto quiere decir que la información particular de cada caso —ésa que para Muñoz nos determina- no es lo que importa; lo que importa es cómo funciona la máquina, cómo y qué hace para poder leer la información.

La única opción que tienen quienes defienden esta idea es tratar también como objeto al sujeto o los sujetos que le otorgan sentido al patrimonio cultural. Lo que tenemos que restaurar (o evitar que se degrade) está otra vez en el objeto, sólo que el objeto es humano. Se está infiriendo que, si recopilamos los atributos o valores con los que este objeto humano (re)conoce el patrimonio cultural, entonces habremos hecho una intervención adecuada. Dicho de otro modo, se equipara inadvertidamente la unidad potencial brandiana con los valores sociales, asumiendo que, si conocemos adecuadamente aquellos que se le atribuyen a un bien cultural dado, podremos restaurar su significado. ${ }^{5}$ La pelota sigue, así, en el terreno del objeto, pero ya ni siquiera con pretensiones objetivas.

Debo señalar aquí que no estoy en contra, ni mucho menos, de que la conservación-restauración se preocupe por los valores que se le atribuyen a los objetos culturales, ni de que de su análisis y, sobre todo, de la deliberación que establezcamos con sus usuarios se obtengan elementos para elaborar una propuesta de intervención específica. Sólo estoy diciendo que me parece que la propuesta de Muñoz no acierta en el camino que necesita seguir la disciplina. Sobre todo porque puede Ilevarnos a pensar que entonces se hace lo "que el cliente pide", dado que parecería que este cliente social es el verdadero y único detentador del sentido de la restauración de un bien cultural. ${ }^{6}$

\footnotetext{
${ }^{5}$ Existe otro tercer problema en esta manera de centrar el problema en los valores que no depende de su función como herramienta de conocimiento, sino de la ridiculización de su uso, que en general resulta en frases absolutamente tautológicas: "la factura de este bien cultural demuestra un desarrollo plástico y un conocimiento tecnológico notables..., es llevado en procesión por las mujeres de la comunidad... Dados los valores detectados en esta pieza, de orden técnico, plástico y de veneración, se vuelve sustantivo restaurarla puesto que, de no hacerlo, éstos se verán afectados en su integridad". Usar esta repetición de obviedades (es venerado, detenta valores religiosos) y juicios de valor (como su ejecución implicó dificultades, tiene atributos tecnológicos relevantes) no sirve de nada. De esto al sistema tradicional de recopilación de antecedentes históricos y estéticos que se usó hasta finales del siglo xx no hay mucha diferencia, $y$, de hecho, en ciertos casos los antecedentes en bruto pueden reflejar mejor los valores en debate.

${ }^{6}$ El propio Muñoz nota este problema y habla de él (2003:177), pero la
} 
Si esto fuera así, nuestro trabajo diferiría bien poco del de un albañil o un carpintero: ambos pueden reparar un objeto para que funcione de nuevo o para que adquiera el aspecto que su dueño quiera darle. Intuitivamente hay una diferencia; conceptualmente también la hay. Insisto, no tiene que recaer necesariamente en el reconocimiento del objeto como obra de arte, pero tampoco únicamente en el reconocimiento del significado que el usuario le ha atribuido (asumiendo, además, que no habría discursos rivales entre los diferentes usuarios o grupos de usuarios, aspecto que Muñoz también reconoce como problemático). ${ }^{7}$

\section{Cuando trabajamos con objetos culturales venerados}

El patrimonio cultural venerado (así sus usuarios lo consideren o no patrimonio cultural) quizá sea el que mejor ejemplifica el problema del relativismo, y el que, como ya se vio también, genera las mayores dudas sobre lo que es lícito hacer durante una intervención de conservación y/o restauración. Otros tipos de patrimonio pueden regirse de acuerdo con lo señalado por la normatividad clásica, pero en este caso en particular resulta especialmente difícil. En este sentido han surgido respuestas muy interesantes desde el ámbito de la gestión:

En la introducción de Conservation of Living Religious Heritage, Herb Stovel (2005) hace notar que, si una institución de la importancia del ICCROM dedicó su foro internacional del 2003 a una serie de estudios de caso sobre la conservación de patrimonio venerado en uso, esto

solución no es satisfactoria: "Algunos lectores quizá concluyan que la teoría contemporánea de la Restauración está diciendo que todo vale, como de hecho parece sugerir el subjetivismo radical: que puesto que los auténticos criterios en los que se basan los trabajos de Restauración son subjetivos, es lícito hacer lo que el sujeto protagonista (el restaurador u otros decididores) prefiera. Pero en realidad está diciendo todo lo contrario. Está diciendo que el restaurador no puede hacer lo que él decida, lo que crea mejor, lo que a él le han enseñado, y que el criterio principal que debería guiar su actuación es la satisfacción del conjunto de sujetos a quiénes su trabajo afecta y afectará en un futuro". Juan Carlos Barbero dice lo mismo quizá más claramente: "Nuestra tarea como restauradores es la de conocer lo que desea el hombre de hoy, y también, sobre todo, la de centrar sus deseos intentando ofrecerle el patrimonio desde su mayor y más eficiente valor expresivo" (Barbero 2003:77).

${ }^{7}$ Este punto nos lleva al interesantísimo problema de la representación. M. A. Bartolomé (1997) lo pone de este modo: "Todo mundo tiene derecho de luchar por su colectividad, pero ello no implica necesariamente ser su representante". Esto es, ¿quién detenta los valores genuinos, o la autoridad real, sobre un determinado tipo de patrimonio? El tema es muy complejo (atañe tanto a problemas tipo Estado-nación vs. sujetos sociales como a problemas inter e intragrupales, pero también puede referirse, por ejemplo, a si el restaurador está tratando con la gente correcta en una determinada población) y es materia de otro tipo de reflexiones que, aunque no tienen cabida en este texto, es importante analizar cuando sea posible. implica de entrada que tal patrimonio se considera distinto a otros, lo cual nos habla de un primer paso muy interesante. ${ }^{8}$ En un texto, también del ICCROM, Webber Ndoro (2005) señala desde su título el problema central que se buscaba detectar y trabajar en el foro del 2003: The Preservation of Great Zimbabwe. Your Monument our Shrine (La preservación del Gran Zimbabue. Su monumento, nuestro santuario). La Australian Heritage Commission también lo nota, y de hecho, propone una serie de lineamientos de gestión para respetar y entender el manejo de sitios y valores patrimoniales indígenas, intitulada Ask First (Primero pregunte).

Estos textos y los esfuerzos que los concretaron nos dicen que, a diferencia de un objeto de museo, en un objeto venerado coexiste una pluralidad de intereses $y$, por tanto, gran cantidad de maneras de entender y solucionar su "deterioro". Estos trabajos de reflexión contemporáneos muestran que si algo se ha aprendido en las disciplinas relacionadas con el manejo y la conservación del patrimonio cultural es que el conocimiento técnico es insuficiente para legitimar una intervención, y que para tomar buenas decisiones es necesario considerar a los diversos actores involucrados en el asunto.

Hasta aquí se ha dicho más o menos lo mismo que la corriente que puede representar Muñoz como extremo máximo, pero se hace hincapié en la deliberación: se asume que ambas partes tienen una información que puede ser socializada. Generalmente, el restaurador realiza la propuesta final de intervención, quien, con el fin de sustentarla lo más objetivamente posible, suele proponer una serie de pasos metodológicos (prospección del sitio u objeto, estudio del deterioro y sus causas, encuestas de opinión, análisis de las leyes de protección de patrimonio cultural vigentes, análisis de las fuentes documentales y gráficas existentes, etcétera).

Pero siendo esto así, antes de preguntarnos por lo que aportan a la deliberación los objetos, el usuario y el contexto, sería importante saber qué es lo que los restauradores específicamente podemos aportar a estos diálogos que los hagan normativos y no meramente casuísticos. Dicho de otro modo, ¿qué es lo que nos constituye como restauradores que nos permite aportar elementos a una deliberación, eso sin lo cual dejaríamos de ser restaura-

\footnotetext{
${ }^{8}$ Curiosamente, varios autores españoles ampliamente consultados en México, como Ana M. Macarrón (2008), el propio Muñoz (2003) o la dupla Tugores y Planas (2006), omiten el tema del patrimonio venerado, aun cuando hacen extensivas revisiones sobre distintos tipos de patrimonio y/o ejemplifican con casos representativos problemas conceptuales y de intervención. Lo más socorrido, en cambio, es pasar directamente a hablar del patrimonio inmaterial y a las formas de preservación que implica. El papel del objeto como evocador de lo intangible es soslayado en todos los casos, prefiriéndose sistemas de registro sonoros, gráficos o documentales de las actividades sociales consideradas bienes intangibles. Stovel también hace notar esto en el ámbito internacional: siendo a su juicio el patrimonio venerado el más abundante, es el menos representado en las cartas y documentos internacionales.
} 
dores (y sin lo cual todas las intervenciones basadas en una deliberación serían siempre un caso único)?

Siguiendo la propuesta de la filósofa neokantiana contemporánea Christine Korsgaard, me gustaría sugerir que lo que para nosotros es constitutivo de la profesión es también lo que la hace normativa respecto de su campo de acción. Para ello rescato la noción de forma a la que ella apela, y para clarificar lo que quiero decir me refiero a una serie de principios que, me parece, definen la actividad de la restauración. Aclaro que lo que pretendo hacer aquí no es proporcionar las herramientas con las que se objetiviza el conocimiento de una pieza (como ya dije: el registro gráfico, la evaluación de su estado de conservación, la discusión con los usuarios, el análisis de cómo es que usan su patrimonio, etcétera, que es lo que básicamente propone el ámbito de la gestión cultural como garantía de la correcta o incorrecta intervención de una pieza o sitio), sino plantear qué es lo que implica esencialmente la actividad de restaurar y por qué es que eso mismo es normativo y universal dentro la disciplina.

Para armar su argumento, Korsgaard (2009:27-34) pone el ejemplo de la casa, cuya función básica es la de servir como un refugio o abrigo habitable. Sus partes son los muros, el techo, las ventanas. Su forma, siguiendo a Aristóteles, sería el arreglo de las partes que la hacen habitable (los muros se juntan entre sí, el techo se coloca sobre ellos, etcétera). La organización unifica las partes y da lugar a un objeto particular de una cierta clase. El fin con el que se hace la casa es lo que une a las partes entre sí. La finalidad es sustancial porque después de todo cualquier persona sabe más o menos para qué sirve una casa e infiere que el techo va sobre los muros, o que para colocar una puerta primero debe existir un vano. Lo que distingue al arquitecto de las demás personas es que, además, sabe cómo el arreglo de esas partes produce un refugio habitable. Conocer un objeto es entenderlo, esto es, no sólo saber qué hace y de qué está hecho, sino también cómo es que el arreglo o conformación de sus partes le permiten hacer lo que supuestamente debe hacer.

Al mismo tiempo, es la propia organización de la forma de la casa la que determina sus normas: una casa con grietas estructurales es menos buena para resistir asentamientos del terreno que otra que no las tiene y que, por lo tanto, estará en mejores condiciones de resistir un fuerte temblor. "La tesis metafísica de la antigüedad de la identificación de lo real con lo bueno inmediatamente viene a la mente porque esta clase de maldad eventualmente nos lleva a la desintegración real del objeto dando lugar otra vez a una serie de cosas no unificadas" (Korsgaard 2009:28. Traducción de la autora).

Ahora bien, es importante distinguir entre una casa buena o una casa mala de una casa que resulta ser buena o mala por razones externas: por ejemplo si la casa le tapa la vista a todo el vecindario es una casa mala para el vecindario, no una casa mala como refugio habitable.
Los estándares normativos que conlleva la organización de las partes de una cosa son sus principios constitutivos: en los casos en que estos principios no son utilizados como guía simplemente no se está realizando esa actividad. Por ejemplo, el principio constitutivo de caminar es poner un pie frente al otro en una secuencia. Si decido poner ambos pies en el suelo al mismo tiempo, estoy parado, no caminando.

La idea de un estándar constitutivo es fundamental: construir una casa que le tapa la vista a los vecinos, dice Korsgaard (2009:29), no deja de ser, si bien mala, una opción posible para esa casa. Lo que no es opcional es que la casa sirva como abrigo, y por tanto tampoco es opcional preguntarse por qué los muros se juntan entre ellos o las puertas se colocan en los vanos. El constructor podrá hacerse preguntas técnicas sobre cómo es mejor o más conveniente juntar los muros, o en qué sentido unirlos, pero una vez que se solucionan estos puntos no hay espacio para suponer que el principio normativo no tiene también fuerza normativa: si no se sigue (no se unen los muros entre sí), simplemente no se está haciendo una casa, sino sólo se está jugando con una serie de partes sin saber cómo unificarlas para que sirvan de abrigo. "Hacer una casa mala no es diferente de hacer una casa buena, simplemente es la misma actividad mal hecha" (Korsgaard 2009:30).

Un mal constructor no necesariamente usa un conjunto de normas distinto; puede perfectamente seguir las normas, pero con equivocaciones: por ejemplo, no seIla bien la unión entre los muros. Pero si es deshonesto, puede estar haciendo las cosas mal para ahorrar dinero en el mortero de las juntas, por lo cual no podemos decir que está tratando de construir una buena casa (ni que está siguiendo las normas). Lo fundamental, en concreto, es que si bien podemos no cumplir por completo el estándar de la norma, al menos debemos tratar de alcanzarla, de modo que estemos haciendo la actividad que decimos que estamos haciendo (el principio especifico de una actividad es a la vez constitutivo y regulativo de la misma). ${ }^{9}$

Además de los principios de acción, hay un conjunto de principios constitutivos que no son verificables en la experiencia. En el caso de los ejemplos de Korsgaard, la buena forma de la casa que sirve como abrigo es verificable: podemos ver las paredes, caminar sobre los techos o constatar que no hay grietas. La mala casa también es

\footnotetext{
${ }^{9}$ Otra manera de ponerlo sería decir que si en español trato de formular una sentencia de acción sin un verbo no estoy hablando español, quizá esté hablando otra cosa o ninguna, pero español no. Uso este ejemplo para decir que un principio constitutivo como lo es el uso de verbo en la acción no es privativo del idioma español, pero aun así le es constitutivo. Para que sea español hay otras cosas que intervienen en la constitución de esa actividad que se llama hablar español, como, por ejemplo, las palabras o los signos de puntuación, pero la forma en que éstos se unen es la que da lugar al español y no a otro idioma (Korsgaard 2009).
} 
fácil de reconocer. Caminar es poner un pie frente al otro en una secuencia. Pero la justicia, por ejemplo, es una entidad que no existe en la experiencia; no es verificable, aunque, sin embargo, subsume experiencias concretas: la justicia nunca ha sido vista caminando por la calle, pero en todos los seres humanos existe una idea de justicia y hemos vivido o visto acciones que nos parecen justas. Seguir los principios que constituyen la justicia es ser justo; no seguirlos, ser injusto. El contenido de qué es lo que consideramos justo variará de persona a persona o de cultura a cultura, pero todos los seres humanos compartimos la idea de que hay algo justo.

Regresando a la conservación-restauración, a mi juicio, y gracias a largas conversaciones con distintos colegas, la conservación-restauración se constituye y norma a partir de tres principios básicos: 1) intenta eliminar un deterioro dado en un objeto dado; 2) busca hacerlo respetando la integridad y autenticidad de ese objeto, y, 3) procura que éste sea usado o gozado por una serie de personas (o ideales: la ciencia, la historia, la nación, etcétera).

Cómo puede hacerse esto es lo que debe deliberarse con los otros dos elementos del triángulo del que hablamos antes (el objeto y sus usuarios): es lo que pongo en la mesa moral, no epistemológicamente.

Un carpintero o un albañil es capaz de detener el deterioro de un objeto cualquiera a petición de un grupo de gente cualquiera, pero no lo hace con el propósito de respetar la autenticidad e integridad de esa cosa. Los principios normativos de los que hablo nunca serían opcionales. El contenido de lo que es auténtico o no; de si lo auténtico recae en los usuarios o en la materia del objeto, es lo que será particular, y será lo que se determinará en cada caso con toda la información que se obtenga del objeto y sus usuarios - ambos considerados, con las herramientas de conocimiento que tenemos como restauradores, como objetos; no así con las herramientas morales que nos constituyen-, como dice el documento de Nara, por ejemplo. Así, un antropólogo quizá quiera documentar el uso de un objeto sacro en un ritual religioso dado, pero no en todos los casos le importará que su deterioro sea avanzado mientras pueda registrarlo adecuadamente (o a lo mucho registrará que se usa aun deteriorado).

En cambio, un restaurador, para serlo cabalmente, no puede, por dar un ejemplo trivial, no preocuparse por la integridad de una pieza a la que le han sustraído la mitad de las partes. No puede sino preguntarse cómo ayudar a que su estructura devenga en una estructura estable, y no puede sino preguntarse por la autenticidad de su materia —o de su uso- y cómo es que logrará respetarla. La combinación y forma en que aparezcan estos principios y se les dé jerarquía unos frente a otros es materia de cada caso, como ya he dicho, pero siempre estarán presentes en la forma en que el restaurador desarrolla su actividad.

Gracias a estos elementos normativos es como el restaurador está en posición de deliberar con los otros: primero usará las otras dos partes del triángulo como receptáculo de información, pero después deberá, necesariamente, dialogar y deliberar con ellos bajo un código normativo que le es (que nos es) propio. La respuesta final, con contenidos claros, viene de la deliberación, pero un restaurador jamás deberá perder de vista que actúa bajo un cierto grupo de principios normativos básicos, así como el objeto nunca dejará de estar hecho materialmente de lo que está hecho cuando se encuentra con él por primera vez (ni una comunidad religiosa rural dejará de intentar que su san Marcos tenga un león, aunque éste ya no exista físicamente en una escultura).

Posteriormente, ayuda bastante proponer lineamientos rígidos de intervención para sentir que se obra con objetividad y metodología epistémica en tipologías de patrimonio (esto debe hacerse cuando se abordan problemas de patrimonio rupestre..., aquello cuando lidiamos con el comité de fiestas de cierto pueblo), pero esto es, subrayo, un paso subsecuente. Tal vez los criterios específicos cambien en determinados momentos o los debates no tengan el resultado final esperado, pero lo que nunca cambiará son los principios normativos que los sustentan. Éstas son las normas constitutivas de nuestra actividad; los principios que la definen y la hacen ser lo que es.

Por ello, y para finalizar, diría que problemas como los que enuncié al principio de este texto pueden o no ser objeto de estudio de la disciplina: la iglesia de Laguna acaso de nuevo sea el lienzo del sueño de los warchiefs y los restauradores deberán ver la autenticidad no en la materia sino en el proceso, y ayudar simplemente a remover los aplanados actuales; o podrán ver como auténtica la pintura vinílica actual, pero deberán preguntarse necesariamente sobre lo que, entonces, la hace su auténtica. En Santa Teresa del Nayar podrán o no restaurar el edificio jesuita, pero indudablemente se preguntarán sobre el destino de un edificio sin cubierta, y a la vez sobre la pertinencia de restaurar un edificio que no será usado. $Y$ después lo conversarán con las otras partes.

Esto parece una obviedad, pero no lo es: basta ver la pasividad normativa con la que se interviene en éstos y otros casos ¿Cuántas veces hemos oído decir: "a los arcángeles de este cuadro les faltan las manos, pero la gente quiere que las tengan; no hay ningún dato que me permita saber cómo eran esas manos, pero, si no lo hago yo, seguramente la comunidad va a conseguir a alguien más que lo haga"? ¿No nos desdibuja terriblemente no reflexionar sobre nuestros principios y conversarlos con la gente? ¿No es el argumento anterior una forma de decir que no se es restaurador sino otra cosa? El resultado y los límites técnicos a los que se llegue quizá no son lo más significativo del debate, aunque sin duda tienen gran importancia. Lo significativo será que seguiremos siendo restauradores en cada intento, y que la mayor parte de las veces - aun con grupos indígenas monolingües y en absoluto diferentes de nosotros culturalmente- podemos 
hacer que las otras partes sopesen y mediten sobre lo que estamos defendiendo o queriendo introducir al debate: que nos conozcan y sopesen nuestras alternativas, así como nosotros intentamos conocerlos a ellos.

\section{Agradecimientos}

Agradezco profundamente a Faviola Rivera, Valerie Magar, Luis Fernando Granados, Fernando Rudy y Rodrigo Díaz todos los comentarios y conversaciones que me permitieron escribir este texto.

\section{Referencias}

\section{AA. VV.}

1964 Carta internacional sobre la conservación y restauración de monumentos y sitios (Carta de Venecia), Venecia, Segundo Congreso Internacional de Arquitectos y Técnicos de Monumentos Históricos.

AA. VV.

Documento de Nara sobre la autenticidad cultural, Nara, UNESCO/Gobierno de Japón/ICCROM/ICOMOS.

Aristóteles

1963 Obras filosóficas. Metafísica, Ética, Política, Poética, selecc. y estudio preliminar de Francisco Romero, trad. de Lilia Segura, México,WM Jackson Editores (Clásicos Jackson).

Australian Heritage Commission 2002 Ask First. A Guide to Respecting Indigenous Heritage Places and Values, Canberra, Australian Heritage Commission.

Avrami, Erica, Randall Mason y Marta de la Torre (coords.) 2000 Values and Heritage Conservation. Research Report, Los Ángeles, Getty Conservation Institute.

Barbero, Juan Carlos

2003 La memoria de las imágenes. Notas para una teoría de la restauración, Madrid, Polifemo.

Bartolomé, Miguel Alberto

1997 Gente de costumbre y gente de razón. Las identidades étnicas en México, México, Siglo XXI/INI.

Brandi, Cesare

1988 [1963] Teoría de la restauración, María Ángeles Toajas Roger (trad.), Madrid, Alianza Forma.

Brunel, Georges

2000 "Introduction", en Cesare Brandi, Théorie de la restauration, París, Monum-Editions du Patrimoine.

Geertz, Clifford

2002 Reflexiones antropológicas sobre temas filosóficos, Nicolás Sánchez y Gloria Llorens (trads.), Barcelona, Paidós (Studio 153).

González-Varas, Ignacio

1999 Conservación de bienes culturales. Teoría, historia, principios y normas, Barcelona, Cátedra (Manuales Arte).
Husserl, Edmund

1986 [1913] Ideas relativas a una fenomenología pura y a una filosofía fenomenológica, José Gaos (trad.), México, FCE (Obras de Filosofía).

Kant, Immanuel

1978 Crítica de la razón pura, Pedro Ribas (ed. y trad.), Madrid, Alfaguara (Los Clásicos).

Kant, Immanuel

1996 Fundamentación de la metafísica de las costumbres, José Mardomingo (ed. y trad.), Barcelona, Ariel (Filosofía).

Korsgaard, Christine

2000 Las fuentes de la normatividad, Laura Lecuona y Laura E. Manríquez (trads.), México, IIF-UNAM (Filosofía Contemporánea).

2009 Self-Constitution. Agency, Identity, and Integrity, Oxford, Oxford University Press.

Macarrón, Ana

2008 Conservación del patrimonio cultural. Criterios y normas, Madrid, Síntesis.

Muñoz, Salvador

2003 Teoría contemporánea de la restauración, Madrid, Síntesis (Patrimonio Cultural).

Ndoro, Webber

2005 The Preservation of Great Zimbabwe. Your Monument our Shrine, Roma, ICCROM (Conservation Studies, 4).

Pearce, Susan M.

2000 "The making of cultural heritage", en Erica Avrami, Randall Mason y Marta de la Torre (coords.), Values and Heritage Conservation. Research Report, Los Ángeles, Getty Conservation Institute, 59-64.

Philippot, Paul

1995 "L'oeuvre d'art, le temps et la restauration", en Histoire de l'art. De la restauration à l'histoire de l'art, 32 : 3-9.

Philippot, Paul

1976 "Historic preservation: Philosophy, criteria, guidelines", en Sharon Timmons (ed.), Preservation and Conservation: Principles and Practices. Proceedings of the North American International Regional Conference, Williamsburg, September 10-16, 1972, Washington, D. C., The Preservation Press.

Stovel, Herb

2005 "Introduction", en Herb Stovel, Nicholas S. Price y Robert Kilick (eds.) Conservation of Living Religious Heritage, Roma, ICCROM (Conservation Studies 3), 1-11.

Torre, Marta de la (coord.) 2002 Assessing the Values of Cultural Hertitage. Research Report, Los Ángeles, Getty Conservation Institute.

Tugores, Francesca y Rosa Planas 2006 Introducción al patrimonio cultural, Gijón,Trea. 


\section{Resumen}

La conservación-restauración de bienes culturales venerados ha demostrado ser una actividad problemática, debido fundamentalmente a la ausencia de un marco conceptual que dé cuenta de sus particularidades específicas. En la teoría clásica de la restauración, por ejemplo, ni siquiera está prevista la relación de los usuarios con los objetos, lo que provoca equívocos "éticos" y soluciones acríticas y aisladas. Los esfuerzos contemporáneos por conceptualizar esta relación entre usuario y objeto venerado tampoco son satisfactorios. El presente texto intenta mostrar que, si bien la conservación-restauración tiene una dimensión epistemológica y otra moral, de la conjunción de abordar ambas esferas a la par surgirá forzosamente una serie de principios normativos que eviten en gran medida intervenciones casuísticas, discusiones retóricas sobre los alcances y posibilidades de nuestro quehacer en dicho ámbito y/o decisiones superficiales decididas bajo presión de los usuarios.

\section{Palabras clave}

Deliberación, epistemología, normatividad.

\section{Abstract}

The conservation and restoration of cultural objects of worship have proved to be a problematic activity, mainly due to the lack of a conceptual frame that considers their specific characteristics. For example, the classic theory of restoration does not take into account the relationship between users and objects. This produces "ethical" ambiguities as well as isolated and uncritical solutions. Contemporary efforts of conceptualizing this relationship between users and objects of worship are not satisfactory either. This paper tries to show that, as conservation-restoration has an epistemological and a moral dimension, if both are addressed at the same time, a series of normative principles will emerge from this union, and to a large degree will prevent casuistic interventions, rhetorical discussions in this field and/or superficial decisions made under the pressure of the users.

\section{Keywords}

Deliberation, epistemology, normativity. 